\title{
ST-segment Elevation Myocardial Infarction Resulting from Stent Thrombosis in Contemporary Real-World Practice
}

\author{
Yumiko Kanei, MD ${ }^{1} \quad$ Kishore Nallu, $M^{1} \quad$ Parth Makker, MD ${ }^{1} \quad$ Supreeti Behuria, MD ${ }^{1}$ John Fox, MD \\ ${ }^{1}$ Department of Cardiology, Mount Sinai Beth Israel, New York, \\ New York \\ Address for correspondence Yumiko Kanei, MD, Department of \\ Cardiology, Mount Sinai Beth Israel, 1st Avenue at 16th Street, \\ Int J Angiol 2017;26:32-35. \\ New York, NY 10003 (e-mail: yumikanei@hotmail.com).
}

\begin{abstract}
Stent thrombosis (ST) is a rare but devastating complication after percutaneous coronary intervention. Newer generation drug-eluting stents (DES) and newer antiplatelet therapies have been shown to decrease the incidence of ST, but we continue to observe ST-segment elevation myocardial infarction (STEMI) due to ST in contemporary practice. A retrospective analysis of 527 patients who presented with STEMI was performed; 57 patients $(11 \%)$ with angiographically confirmed ST were compared with the patients with STEMI due to de novo lesion. The type of previous stent, the timing of ST, and the use of antiplatelet therapy were reviewed in patients with ST. Patients with ST had higher prevalence of comorbid conditions, such as hypertension, diabetes mellitus, and coronary artery disease, and had lower left ventricular ejection fraction ( $37 \pm 5$ vs. $44 \pm 16 \%, p=0.0011$ ). There was no difference in in-hospital

Keywords

- stent

- myocardial infarction

- cardiac catheterization

- coronary intervention

- neoatherosclerosis mortality ( 2 vs. $4 \%, p=0.7082$ ). ST was seen most commonly as "very late" $(56 \%)$, and with previous second-generation DES (40\%). Eighty-two percent of patients among early ST, compared with $22 \%$ of patients with very late ST were on dual antiplatelet therapy (DAPT). In $12 \%$ of patients, ST happened after DAPT was stopped by physician for procedures. ST is seen in a variety of clinical settings with the most common presentation being very late ST and in second-generation DES, which most likely represent the growing population with previous second-generation stents.
\end{abstract}

Percutaneous coronary intervention (PCI) with stent placement is a standard treatment of obstructive coronary artery disease. Stent thrombosis (ST), although rare, is a devastating complication after PCI and results in significant morbidity and mortality. ${ }^{1}$ The incidence of ST is estimated to be $<1 \%$ in randomized trials and most commonly occurs early, in the first 30 days after stent placement. ${ }^{1,2}$ Recently, the use of more potent antiplatelet thera$\mathrm{py}^{3,4}$ and second-generation drug-eluting stents (DES) ${ }^{2,5}$ has been shown to reduce the incidence of ST. The aim of this study was to describe the incidence and the characteristics of patients who presented with ST-segment elevation myocardial infarction (STEMI) due to ST in contemporary real-world practice.

\section{Methods}

\section{Study Population}

A single-center retrospective analysis was performed on 527 patients who presented with STEMI and underwent emergent coronary angiography and PCI from 2007 to 2014 at the Mount Sinai Beth Israel Hospital. All patients with STEMI who underwent emergency PCI were included in this study without exclusion. STEMI was diagnosed according to the American College of Cardiology and European Society of Cardiology criteria (i.e., chest pain persisting $\geq 30$ minutes associated with ST-segment elevation $\geq 0.1 \mathrm{mV}$ in $\geq 2$ continuous electrocardiographic leads). ${ }^{6}$ published online

December 26, 2016
Copyright @ 2017 by Thieme Medical Publishers, Inc., 333 Seventh Avenue, New York, NY 10001, USA. Tel: +1(212) 584-4662.
DOI http://dx.doi.org/ 10.1055/s-0036-1593828. ISSN 1061-1711. 


\section{Data Collection}

A team of researchers independently reviewed the emergency department records, in-hospital admission records, and cardiac catheterization studies. The clinical characteristics of the patients were recorded into a database and included comorbid conditions such as hypertension, diabetes mellitus, dyslipidemia, and history of prior coronary artery disease requiring revascularization. Coronary angiography was reviewed by an experienced interventional cardiologist. ST was defined according to the Academic Research Consortium definition with angiographic confirmation of "definite" ST. The timing of ST was defined as "acute" (within 24 hours), "subacute" (within 1 month), "late" (within 1 year), and "very late" (after 1 year). ${ }^{6}$ Angiographic and procedural characteristics such as culprit artery, thrombolysis in myocardial infarction (TIMI) flow grade, and multivessel involvement were also documented. In patients who presented with ST, information regarding the type of previous stent, timing of the event, and the use of and compliance with antiplatelet therapy were extracted from the medical record. Dual antiplatelet therapy (DAPT) was defined as the use of aspirin along with one of the P2Y12 inhibitors (clopidogrel, prasugrel, and ticagrelor). In-hospital clinical events (death, recurrent myocardial infarction, target vessel revascularization) and peak cardiac enzymes were recorded as clinical outcomes.

\section{Statistical Analysis}

Clinical and procedural characteristics were compared between patients who presented with ST and those without ST. Continuous variables were compared using Student $t$-test. Categorical variables were compared using chi-square test or Fisher exact test. A $p$-value of less than 0.05 was regarded as statistically significant.

The present study complied with the declaration of Helsinki and was approved by the Institutional Review Board of our institution.

\section{Results}

Among 527 patients with STEMI, 57 patients (11\%) had angiographically confirmed stent thrombosis. Patients in the ST group had a higher prevalence of comorbid conditions such as diabetes mellitus ( 46 vs. $24 \%, p=0.0009$ ), hypertension (72 vs. $52 \%, p=0.0071$ ), dyslipidemia (67 vs. $40 \%$, $p=0.0003$ ), prior MI (32 vs. $6 \%, p \leq 0.0001$ ), and prior coronary artery bypass grafting (12 vs. $2 \%, p=0.0004)$. Three-vessel disease was more common in patients with ST than in the non-ST group (28 vs. $14 \%, p=0.0106$ ) (- Table 1 ).

The ejection fraction was lower in patients with ST (37 $\pm 5 \%$ ) compared with the non-ST group $(44 \pm 16 \%)(p=0.0011)$. Median peak creatine phosphokinase (CPK) was higher in the ST group than in the non-ST group; however, this was not statistically significant (2,319 vs. $1,508 \mathrm{IU} / \mathrm{L}, p=0.084$ ). A higher post-PCI TIMI 3 flow was seen in the ST group compared with the non-ST group (84 vs. $79 \%, p=0.003$ ). In-hospital mortality was low in general, and did not differ between the two groups ( 2 vs. $4 \%, p=0.7082$ ) (-Table 1 ).

ST was seen most commonly as "very late" (56\%) ST followed by "subacute" (25\%) ST. Eleven patients with ST
Table 1 Clinical and procedural characteristics of patients who presented with and without ST

\begin{tabular}{|c|c|c|c|}
\hline & $\begin{array}{l}\text { ST } \\
N=57\end{array}$ & $\begin{array}{l}\text { No ST } \\
N=470\end{array}$ & $p$-Value \\
\hline \multicolumn{4}{|c|}{ Clinical characteristics } \\
\hline Age & $63 \pm 12$ & $60 \pm 13$ & 0.0978 \\
\hline Male & $41(72 \%)$ & $375(80 \%)$ & 0.2294 \\
\hline Hypertension & $41(72 \%)$ & $245(52 \%)$ & 0.0071 \\
\hline $\begin{array}{l}\text { Diabetes } \\
\text { mellitus }\end{array}$ & $26(46 \%)$ & $113(24 \%)$ & 0.0009 \\
\hline Dyslipidemia & $38(67 \%)$ & $190(40 \%)$ & 0.0003 \\
\hline $\begin{array}{l}\text { Current } \\
\text { smoking }\end{array}$ & $17(30 \%)$ & $188(40 \%)$ & 0.2193 \\
\hline $\begin{array}{l}\text { Prior myocardial } \\
\text { infarction }\end{array}$ & $18(32 \%)$ & $28(6 \%)$ & $<0.0001$ \\
\hline Prior $\mathrm{PCl}$ & $57(100 \%)$ & $38(8 \%)$ & $<0.0001$ \\
\hline Prior CABG & $7(12 \%)$ & $8(2 \%)$ & 0.0004 \\
\hline \multicolumn{4}{|c|}{ Procedural characteristics and hospital course } \\
\hline \multicolumn{4}{|l|}{ Culprit artery } \\
\hline LAD & $30(53 \%)$ & $200(43 \%)$ & 0.1910 \\
\hline LCx & $5(9 \%)$ & $55(12 \%)$ & \\
\hline RCA & 19 (33\%) & $192(41 \%)$ & \\
\hline $\begin{array}{l}\text { Diagonal } \\
\text { branch }\end{array}$ & $1(2 \%)$ & $8(2 \%)$ & \\
\hline LM & 0 & $4(1 \%)$ & \\
\hline Graft & $2(4 \%)$ & $6(1 \%)$ & \\
\hline Stent & 39 (68\%) & 455 (97\%) & $<0.0001$ \\
\hline Initial TIMI 0 & 52 (91\%) & $318(68 \%)$ & $<0.0001$ \\
\hline Final TIMI 3 & 48 (84\%) & 370 (79\%) & 0.0029 \\
\hline $\begin{array}{l}\text { Three-vessel } \\
\text { disease }\end{array}$ & $16(28 \%)$ & $66(14 \%)$ & 0.0106 \\
\hline IABP & $8(14 \%)$ & 73 (16\%) & 1.0000 \\
\hline GP IIb/IIla inhibitor & $28(49 \%)$ & $167(36 \%)$ & 0.0626 \\
\hline $\begin{array}{l}\text { Left ventricular } \\
\text { ejection fraction } \\
\text { (\%) }\end{array}$ & $37 \pm 5$ & $44 \pm 16$ & 0.0011 \\
\hline $\begin{array}{l}\text { Median peak } \\
\text { creatine kinase } \\
(\mathrm{U} / \mathrm{L})\end{array}$ & $\begin{array}{l}2,319 \\
(155-16,750)\end{array}$ & $\begin{array}{l}1,508 \\
(50-14,981)\end{array}$ & 0.084 \\
\hline In-hospital death & $1(2 \%)$ & $17(4 \%)$ & 0.7082 \\
\hline
\end{tabular}

Abbreviations: CABG, coronary artery bypass grafting; IABP, intra-aortic balloon pump; LAD, left anterior descending; LCx, left circumflex; LM, left main; $\mathrm{PCl}$, percutaneous coronary intervention; RCA, right coronary artery; ST, stent thrombosis; TIMI, thrombolysis in myocardial infarction.

(19\%) had bare metal stents, 19 patients (34\%) had firstgeneration DES, and 23 patients (40\%) had second-generation DES. Stent type was unknown in 4 patients (7\%). Of the patients presenting with ST, 24 patients (42\%) were taking DAPT at the time of the event. Although $82 \%$ of patients who presented with early ST were on DAPT, only $22 \%$ of patients with very late ST were on DAPT ( - Fig. 1). Premature termination of DAPT was seen in seven patients (12\%) due to 


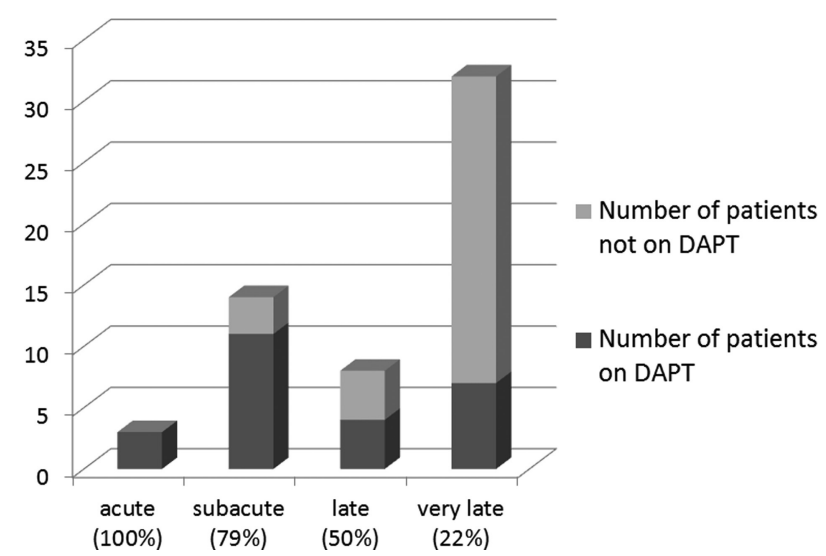

Fig. 1 The timing of stent thrombosis and the number of patients who were on DAPT; $100 \%$ of acute, $79 \%$ of subacute, $50 \%$ of late, and $22 \%$ of very late stent thromboses were taking DAPT. DAPT, dual antiplatelet therapy.

noncompliance or social circumstances. In 7 patients (12\%), DAPT was held by a physician appropriately prior to a surgery or a procedure.

\section{Discussion}

Although ST is an uncommon complication after PCI, it carries significant morbidity and mortality. Patients with ST generally present with large STEMI, and PCI of ST has been shown previously to have a lower successful reperfusion rate. ${ }^{7}$ ST accounted for 3 to $8.5 \%$ of cases of STEMI in previous registries, $^{8-10}$ and recent data have shown that the relative prevalence is increasing. ${ }^{8}$ In our cohort of patients with STEMI, ST was seen in $11 \%$ of cases. Patients with STEMI due to ST were reported to have mortality ranging from 11 to $42 \%$, with higher in-hospital mortality than those with a STEMI due to a native coronary lesion. ${ }^{7}$ Recent data suggest lower mortality than previously reported, with early ST having higher in-hospital mortality than late or very late ST $(7.9,3.8$, and $3.6 \%$, respectively, $p<0.001)^{11,12}$ Our in-hospital mortality in patients who presented with STEMI due to ST was $2 \%$.

Prospective studies have shown that most cases of ST occur early, within 30 days of stent placement. In the Dutch Stent Thrombosis Registry of 21,009 patients, $73 \%$ of ST occurred within 30 days. ${ }^{13}$ However, in large registries of patients with STEMI, the most common presentation of ST was very late ST, 8,14 likely due to the increasing number of patients at risk for very late ST. In our cohort of patients, more than $50 \%$ of patients presented with very late ST. Although first-generation DES showed increased risk of very late ST, secondgeneration DES ${ }^{5,15}$ have been shown to reduce the incidence of ST. However, $40 \%$ of patients in our cohort who presented with ST had ST of second-generation DES. This may be reflective of our current standard practice with increasing use of second-generation stents.

The mechanism of ST is thought to be multifactorial including factors related to patients, stents, lesions, and procedures. Early cessation of DAPT, undersizing of the coronary stent, malignancy, and intermediate lesion proximal to the culprit lesion were reported to be predictors of ST. ${ }^{13}$ Although early ST is more likely associated with procedural factors, late ST is thought to be associated with delayed endothelial coverage, persistent fibrin deposition, and ongoing vessel inflammation. International registries of 492 cases of late/very late ST could not identify strong predictors for late/very late ST. ${ }^{16}$ Recently, neoatherosclerosis has been suggested as the mechanism of very late ST. Optimal coherence tomography images of 33 patients with very late ST showed that the neointimal rupture and thrombosis were the most common mechanisms of definite very late ST. ${ }^{17}$

The duration of DAPT post-PCI remains an on-going debate. The current ACC guidelines state a class IB recommendation to continue DAPT for 12 months following stent placement. ${ }^{18} \mathrm{~A}$ recently published DAPT study has shown significantly reduced risk of ST with 30 months of DAPT poststent placement. ${ }^{19}$ In our population, $42 \%$ of patients were taking DAPT at the time of the event, and only $22 \%$ of patients who presented with very late ST were taking DAPT. Noncompliance was seen in $12 \%$ of patients, but $12 \%$ of patients were told by their physician to hold DAPT for a procedure, which represents a challenge to our daily practice. The large PARIS registry studied the pattern of DAPT cessation, and concluded DAPT disruption (premature discontinuation), especially in the first 7 days, was strongly associated with increased risk of ST. ${ }^{20}$

Our study has several limitations including those usually associated with retrospective observational studies. Our small sample size does not allow us to evaluate clinical outcomes, and long-term follow-up was not routinely available. As for the procedure, intravascular ultrasound was not routinely used, which could have added more value to the data regarding stent malapposition and stent expansion, which are thought to be predictors of ST.

\section{Conclusion}

In our real-world practice, ST was the cause of STEMI in $11 \%$ of patients. ST can be seen in a variety of clinical settings and the most common presentation was very late ST. Moreover, we observed that $40 \%$ of ST occurred in second-generation DES. With an increasing number of patients at risk, ST will continue to be a challenge facing contemporary practice.

Disclosure

None.

\section{References}

1 Iakovou I, Schmidt T, Bonizzoni E, et al. Incidence, predictors, and outcome of thrombosis after successful implantation of drugeluting stents. JAMA 2005;293(17):2126-2130

2 Palmerini T, Kirtane AJ, Serruys PW, et al. Stent thrombosis with everolimus-eluting stents: meta-analysis of comparative randomized controlled trials. Circ Cardiovasc Interv 2012;5(3):357-364

3 Wiviott SD, Braunwald E, McCabe CH, et al; TRITON-TIMI 38 Investigators. Prasugrel versus clopidogrel in patients with acute coronary syndromes. N Engl J Med 2007;357(20):2001-2015 
4 Wallentin L, Becker RC, Budaj A, et al; PLATO Investigators. Ticagrelor versus clopidogrel in patients with acute coronary syndromes. N Engl J Med 2009;361(11):1045-1057

5 Räber L, Magro M, Stefanini GG, et al. Very late coronary stent thrombosis of a newer-generation everolimus-eluting stent compared with early-generation drug-eluting stents: a prospective cohort study. Circulation 2012;125(9):1110-1121

6 Thygesen K, Alpert JS, Jaffe AS, et al; Joint ESC/ACCF/AHA/WHF Task Force for Universal Definition of Myocardial Infarction; Authors/Task Force Members Chairpersons; Biomarker Subcommittee; ECG Subcommittee; Imaging Subcommittee; Classification Subcommittee; Intervention Subcommittee; Trials \& Registries Subcommittee; Trials \& Registries Subcommittee; Trials \& Registries Subcommittee; Trials \& Registries Subcommittee; ESC Committee for Practice Guidelines (CPG); Document Reviewers. Third universal definition of myocardial infarction. J Am Coll Cardiol 2012;60(16):1581-1598

7 Chechi T, Vecchio S, Vittori G, et al. ST-segment elevation myocardial infarction due to early and late stent thrombosis a new group of high-risk patients. J Am Coll Cardiol 2008;51(25):2396-2402

8 Brodie BR, Hansen C, Garberich RF, et al. ST-segment elevation myocardial infarction resulting from stent thrombosis: an enlarging subgroup of high-risk patients. J Am Coll Cardiol 2012;60(19): 1989-1991

9 Ergelen M, Gorgulu S, Uyarel H, et al. The outcome of primary percutaneous coronary intervention for stent thrombosis causing ST-elevation myocardial infarction. Am Heart J 2010;159(4):672-676

10 Parodi G, Memisha G, Bellandi B, et al. Effectiveness of primary percutaneous coronary interventions for stent thrombosis. Am J Cardiol 2009;103(7):913-916

11 Armstrong EJ, Feldman DN, Wang TY, et al. Clinical presentation, management, and outcomes of angiographically documented early, late, and very late stent thrombosis. JACC Cardiovasc Interv 2012;5(2):131-140

12 Secemsky EA, Matteau A, Yeh RW, et al; PROTECT Trial Investigators. Comparison of short- and long-term cardiac mortality in early versus late stent thrombosis (from Pooled PROTECT Trials). Am J Cardiol 2015;115(12):1678-1684

13 van Werkum JW, Heestermans AA, Zomer AC, et al. Predictors of coronary stent thrombosis: the Dutch Stent Thrombosis Registry. J Am Coll Cardiol 2009;53(16):1399-1409

14 Yeo KK, Mahmud E, Armstrong EJ, et al. Contemporary clinical characteristics, treatment, and outcomes of angiographically confirmed coronary stent thrombosis: results from a multicenter California registry. Catheter Cardiovasc Interv 2012;79(4):550-556

15 Tada T, Byrne RA, Simunovic I, et al. Risk of stent thrombosis among bare-metal stents, first-generation drug-eluting stents, and second-generation drug-eluting stents: results from a registry of 18,334 patients. JACC Cardiovasc Interv 2013;6(12):1267-1274

16 Waksman R, Kirtane AJ, Torguson R, et al; DESERT Investigators. Correlates and outcomes of late and very late drug-eluting stent thrombosis: results from DESERT (International Drug-Eluting Stent Event Registry of Thrombosis). JACC Cardiovasc Interv 2014;7(10):1093-1102

17 Kang SJ, Lee CW, Song H, et al. OCT analysis in patients with very late stent thrombosis. JACC Cardiovasc Imaging 2013;6(6): 695-703

18 Levine GN, Bates ER, Blankenship JC, et al; American College of Cardiology Foundation; American Heart Association Task Force on Practice Guidelines; Society for Cardiovascular Angiography and Interventions. 2011 ACCF/AHA/SCAI Guideline for Percutaneous Coronary Intervention. A report of the American College of Cardiology Foundation/American Heart Association Task Force on Practice Guidelines and the Society for Cardiovascular Angiography and Interventions. J Am Coll Cardiol 2011;58(24):e44-e122

19 Mauri L, Kereiakes DJ, Yeh RW, et al; DAPT Study Investigators. Twelve or 30 months of dual antiplatelet therapy after drugeluting stents. N Engl J Med 2014;371(23):2155-2166

20 Mehran R, Baber U, Steg PG, et al. Cessation of dual antiplatelet treatment and cardiac events after percutaneous coronary intervention (PARIS): 2 year results from a prospective observational study. Lancet 2013;382(9906):1714-1722 